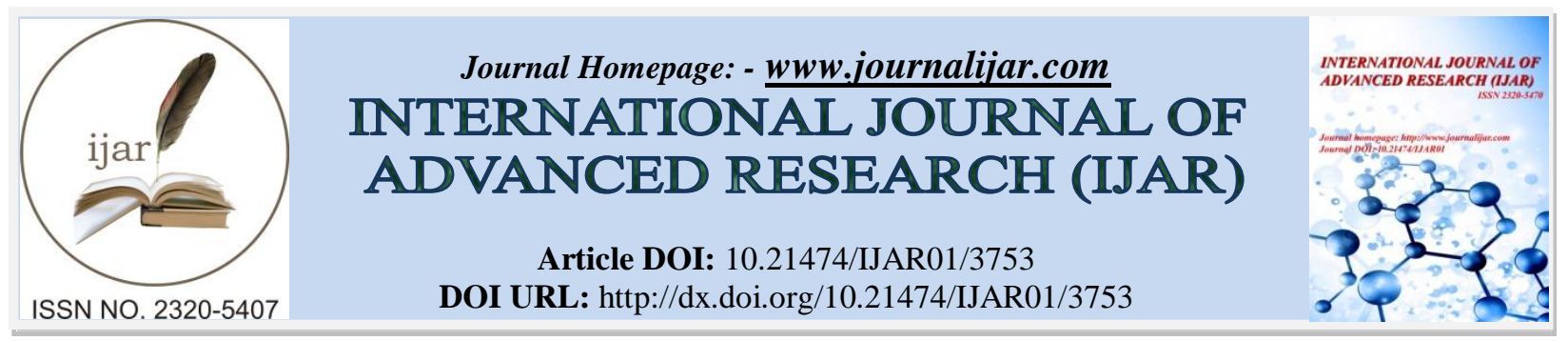

RESEARCH ARTICLE

\title{
SLEEP QUALITY, DAYTIME SLEEPINESS, AND DEPRESSION AMONG ER PHYSICIANS IN RIYADH'S REFERRAL HOSPITALS..
}

Prof. Ahmed Bahammam, Awad Olaish, Aseel Al-Ghonimy, Malak Al Aboudi and Rawan Al Abdullah. King Saud University, College of Medicine, Department of Family \& Community Medicine, CMED 305 course $2015-2016$.

\section{Manuscript Info}

Manuscript History

Received: 16 January 2017

Final Accepted: 08 February 2017

Published: March 2017

Key words:-

ER physicians, sleep quality, daytime sleepiness, depression.

\section{Abstract}

Objectives: To assess the prevalence of daytime sleepiness, poor sleep quality and depression among (emergency room) ER physicians in comparison to family medicine physicians.

Methods: We compared 68 ER physicians with 69 family medicine physicians in an observational case control study. A self-administered questionnaire composed of the Epworth Sleepiness Scale (ESS), the Pittsburgh Sleep Quality Index (PSQI) and the Beck Depression Inventory Scale (BDI).

Results: The mean total ESS score of ER physicians was significantly higher than the score of family medicine physicians as $41.2 \%$ of ER physicians scored $\geq 10$, while only $14.5 \%$ of family medicine physicians scored $\geq 10$. Moreover, ER physicians had a higher on the PSQI (indicating poorer sleep quality), and $83.8 \%$ of them had poor sleep quality $(\geq 5)$ in comparison to $50.7 \%$ of family medicine physicians. The BDI scores of the ER and family medicine physicians indicated that $41 \%$ and $22 \%$ suffered from some level of mood disturbance, respectively. Pearson correlation showed a positive and significant relationship between sleep quality and depression among ER physicians $(\mathrm{P}<0.001, \mathrm{r}=0.437)$.

Conclusion: Our study demonstrated that daytime sleepiness, poor sleep quality and depression are prevalent among ER physicians. Moreover, there was a strong correlation between poor sleep quality and depression.

Copy Right, IJAR, 2017,. All rights reserved.

\section{Introduction:-}

Night shift work is a well-known risk factor for disturbed circadian rhythm ${ }^{1}$, leading to significant drawbacks in quality of sleep and sleep efficiency ${ }^{2-4}$. Therefore, night shift workers, such as emergency room physicians, have a significant liability to develop poor sleep quality. A fair number of studies have focused on the effects of shift work on the general health, and have found a link between shift work and cardiovascular diseases ${ }^{6-12}$, diabetes mellitus type $2^{13-17}$, breast canser ${ }^{21}$, metabolic syndrome ${ }^{22-23}$, memory loss ${ }^{24}$ and obesity ${ }^{25-26}$. In contrast, fewer studies have addressed the relation between shift work and its effect on sleep quality and it is negative consequences on sleep patterns and mood. Shift work schedule has numerous effects on the quality of sleep and wakefulness of workers ${ }^{25}$

27. Some studies mentioned that the irregular work hours seem to exert acute effects on sleep and alertness of individuals similar to those witnessed in clinical insomnia, which could be responsible for major negative human

Corresponding Author:- Prof. Ahmed Bahammam.

Address:- King Saud University, College of Medicine, Department of Family \& Community Medicine, 
and economic impacts due to fatigue related accidents and diminished productivity ${ }^{25}$. There is a definite association between low sleep quality and shift work ${ }^{27,28}$. A previous study done in Kingdom of Saudi Arabia revealed that the quality of sleep of shift-workers was significantly affected in comparison to those without shift work ${ }^{29}$. Sleepiness and stress are among the risk factors for worsening sleep quality among shift workers ${ }^{30}$. Poor sleep quality was associated with increased work injury ${ }^{30}$. Low sleep quality was reported to correlate with a poor quality of life among nurses working rotating shifts ${ }^{28}$. Insomnia among shift workers plays a role in experiencing sleep difficulties ${ }^{31}$. Regarding poor sleep quality and depression, one study was done on multiple sclerosis patient had found a link between poor sleep quality and depression ${ }^{32}$. One studies suggested that the increase in depressive symptoms across adolescence is partially mediated by sleep-related developmental changes ${ }^{33}$. Increasing depression among sleep apnea patients was associated with poor sleep quality, as well ${ }^{34}$.

No study has assessed the effect of shift work on ER physicians on sleep and mood in Saudi Arabia; therefore, we conducted this study to estimate the prevalence of poor sleep quality, daytime sleepiness, and depression among ER physicians.

\section{Methods:-}

This is an observational case control study that was conducted between November 2015 and April 2016. The cases were randomly chosen and comprised of 68 emergency medicine physicians from 8 major Riyadh hospitals (King Khalid University Hospital, King Faisal Specialist Hospital and Research Center, King Fahad Medical City, National Guard Hospital, Prince Sultan Military Medical City, King Saud Medical Complex, Imam Abdulrahman bin Faisal Hospital, King Salman Hospital) who have worked regular shifts for at least 3 months. The controls comprised of 69 family physicians randomly chosen from 5 major Riyadh Hospitals (King Khalid University Hospital, King Fahad Medical City, National Guard Hospital, Prince Mohammed bin Abdulaziz Hospital, King Saud Medical Complex). The project was approved by the Ethics Committee and informed consent was obtained from participants.

\section{Data collection and Questionnaire:-}

As medicine is taught in English in Saudi Arabia, a self-administered questionnaire in the English language was distributed to all participating physicians. The questionnaire used in this study was composed of four sectionsDemographic information, position, previous diagnosis of either depression or a sleeping disorder, and medications.

The Epworth Sleepiness Scale (ESS): This is a validated questionnaire that is used to assess daytime sleepiness. It contains 8 items that assess the likelihood of dozing in a variety of daily living situations. The highest score is 24 , and a score $\geq 10$ indicates sleepiness ${ }^{36}$.

The Pittsburgh Sleep Quality Index questionnaire: This is an instrument used to measure the quality and patterns of sleep in adults. It differentiates "poor" from "good" sleep quality by measuring seven areas (components): subjective sleep quality, sleep latency, sleep duration, habitual sleep efficiency, sleep disturbances, use of sleeping medications, and daytime dysfunction over the last month. A total score of 5 or higher is indicative of poor sleep quality $^{35}$.

The Beck Depression Inventory: This is a validated questionnaire to assess depression. It is composed of items relating to symptoms of depression. It contains 21 questions; each answer being scored on a scale value of 0 to 3 . Higher total scores indicate more severe depressive symptoms. A score of 11-16 indicates mild mood disturbance, 17-20 indicates borderline clinical depression, 21-30 indicates moderate depression, 31-40 indicates severe depression, and a score of over 40 indicates extreme depression ${ }^{37}$.

\section{Data Analysis:-}

Data were expressed as mean \pm SD for continuous data. Categorical data were expressed as $\mathrm{n}(\%)$. Student $\mathrm{t}$-test or Mann-Whitney U-test (depending on normality) and chi-square test were used to compare numerical or categorical data, respectively. One way ANOVA or Kruskal Wallis test (if normality assumption violated) were used to compare BDI groups. The results were considered statistically significant if $\mathrm{P} \leq 0.05$. Pearson correlation or Spearman rank-order correlation (if normality assumption violated) were used to assess correlation between ESS, PSQI and BDI scores. Statistical Package for Social Sciences (SPSS), IBM version 22 (SPSS Inc., Chicago, IL, USA) software was used for data analysis and management. 


\section{Results:-}

The study included 68 ER physicians and 69 family medicine physicians. Table 1 shows that the two groups were similar in all parameters except for age; the mean age for ER physicians was 35.2 years (SD: 8.6), and mean age of 40.4 (SD:10.5) in family medicine physicians. There was a difference in the position parameter, as well. There were a higher proportion of male physicians in both groups; $70.6 \%$ of ER physicians were males, and $58 \%$ were males in family medicine physicians group. One subject of ER physicians reported being diagnosed with a sleeping disorder, and two from the control group, one of them specified being diagnosed with obstructive sleep apnea. In addition, $8.8 \%$ of ER physicians are diagnosed with depression; almost the same percentages, $8.7 \%$, of family medicine physicians are diagnosed with depression as well. Three subjects of the ER physicians reported being on Selective Serotonin Reuptake Inhibitors, and one reported being on beta-adrenergic blocking agents. Only one subject of family medicine physicians is on beta-adrenergic blocking agents.

The mean total ESS score of ER physicians was significantly higher than the score of family medicine physicians. Furthermore, $41.2 \%$ of ER physicians scored $\geq 10$, while only $14.5 \%$ of family medicine physicians scored $\geq 10$ [Table 2]. ER physicians also scored higher on the PSQI, 83.8\% of them were having poor sleep quality ( $\geq 5$ ) in comparison to $50.7 \%$ of family medicine physicians [Table 2]. Finally, a strong correlation was observed between sleep quality and depression among ER physicians, Pearson correlation shows a positive and significant relation (P $<0.001, \mathrm{r}=0.437$ ) [Figure, Table 3]. The results of Pearson correlation between ESS score and BDI score represents that daytime sleepiness has a weak correlation with depression in ER physicians $(r=0.172)$ [Figure, Table 3]. Pearson correlation between sleep quality and daytime sleepiness has a weak correlation $(r=0.178)$, as well. [figure, Table 3].

Table I:- Characteristics; comparison between ER physicians and family medicine physicians.

\begin{tabular}{|c|c|c|c|}
\hline \multirow[t]{2}{*}{ Variable } & \multicolumn{2}{|l|}{ Mean \pm SD } & \multirow[t]{2}{*}{ P-Value } \\
\hline & $\begin{array}{l}\text { ER physicians } \\
\mathrm{n}=68\end{array}$ & $\begin{array}{l}\text { Family medicine } \\
n=69\end{array}$ & \\
\hline Age & $35.2 \pm 8.6$ & $40.4 \pm 10.5$ & 0.003 \\
\hline \multicolumn{4}{|l|}{ Gender } \\
\hline Female & $20(29.4)$ & $29(42)$ & 0.123 \\
\hline Male & $48(70.6)$ & $40(58)$ & \\
\hline \multicolumn{4}{|l|}{ Marital Status } \\
\hline Single & $17(25)$ & $12(17.4)$ & 0.276 \\
\hline Married/Divorced/Widower/Widow & $51(75)$ & $57(82.6)$ & \\
\hline \multicolumn{4}{|l|}{ Position } \\
\hline Consultant & $13(19.1)$ & $26(38.2)$ & 0.014 \\
\hline Assistant professor/Registrar/Resident & $55(80.9)$ & $42(61.8)$ & \\
\hline \multicolumn{4}{|l|}{ Diagnosed with a sleeping disorder } \\
\hline No & $67(98.5)$ & $67(97.1)$ & 1.000 \\
\hline Yes & $1(1.5)$ & $2(2.9)$ & \\
\hline \multicolumn{4}{|l|}{ Sleep Disorders Diagnoses } \\
\hline OSA & $0(0)$ & $1(1.4)$ & 1.000 \\
\hline \multicolumn{4}{|l|}{ Diagnosed with depression } \\
\hline No & $62(91.2)$ & $63(91.3)$ & 0.979 \\
\hline Yes & $6(8.8)$ & $6(8.7)$ & \\
\hline \multicolumn{4}{|l|}{ Medication } \\
\hline Not on medication & $64(94.1)$ & $68(98.6)$ & \multirow[t]{2}{*}{0.208} \\
\hline On Medication & $4(5.9)$ & $1(1.4)$ & \\
\hline
\end{tabular}


Table II:- ESS, PSQI and BDI results, comparison between ER physicians and family medicine physicians.

\begin{tabular}{|c|c|c|c|}
\hline \multirow[t]{2}{*}{ Variable } & \multicolumn{2}{|l|}{ Mean $\pm S D$} & \multirow[t]{2}{*}{ P-Value } \\
\hline & $\begin{array}{l}\text { ER physicians } \\
n=68\end{array}$ & $\begin{array}{l}\text { Family medicine } \\
n=69\end{array}$ & \\
\hline EES Score & $9.1 \pm 4.6$ & $6.1 \pm 3.8$ & $<0.001$ \\
\hline $\begin{array}{r}\text { ESS Diagnostic } \\
<10 \\
\geq 10\end{array}$ & $\begin{array}{l}40(58.8) \\
28(41.2)\end{array}$ & $\begin{array}{l}59(85.5) \\
10(14.5)\end{array}$ & $<0.001$ \\
\hline Global PSQI Score & $8.3 \pm 4$ & $5.3 \pm 3.2$ & $<0.001$ \\
\hline $\begin{array}{r}\text { PSQI Diagnostic } \\
\geq 5 \\
<5\end{array}$ & $\begin{array}{l}57(83.8) \\
11(16.2)\end{array}$ & $\begin{array}{l}35(50.7) \\
34(49.3)\end{array}$ & $<0.001$ \\
\hline BDI Score & $11.5 \pm 10.1$ & $6 \pm 7.1$ & $<0.001$ \\
\hline
\end{tabular}

ESS: Epworth Sleepiness Scale

PSQI: Pittsburgh Sleep Quality Index

BDI: The Beck Depression Inventory

Table III:- Correlations between ESS, PSQI and BDI scores in ER physicians.

\begin{tabular}{|l|c|l|}
\hline Variable & $\mathbf{r}$ & $\mathbf{p}$-Value \\
\hline ESS Score Vs Global PSQI Score & 0.178 & 0.146 \\
\hline ESS Score Vs BDI Score & 0.172 & 0.161 \\
\hline BDI Score Vs Global PSQI Score & 0.437 & $<0.001$ \\
\hline
\end{tabular}

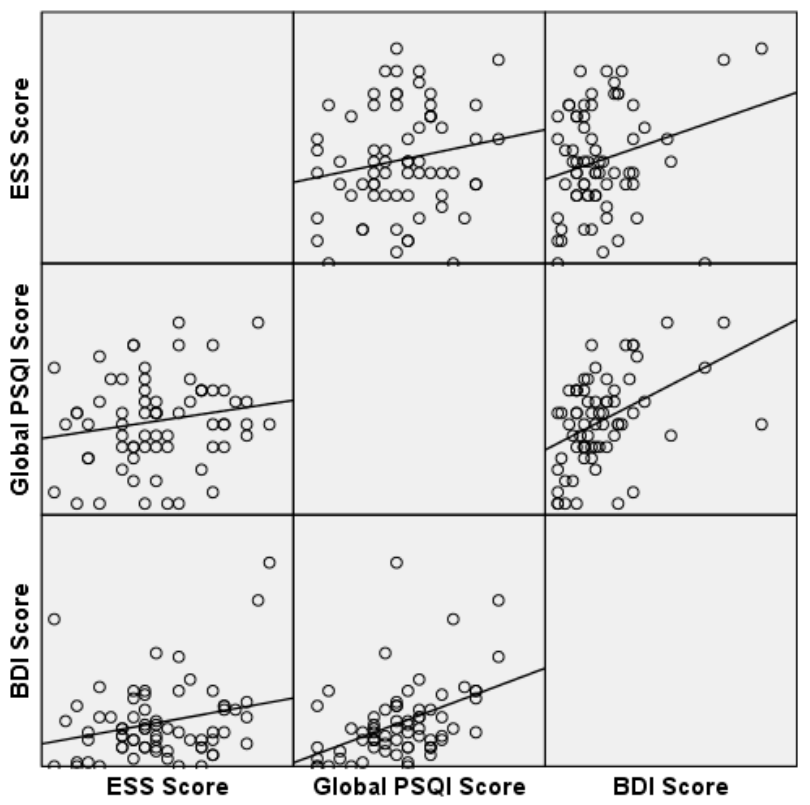

Figure:- Scatter plot between ESS, PSQI and BDI scores in ER physicians.

\section{Discussion:-}

This study was conducted to assess the prevalence of daytime sleepiness, poor sleep quality and depression among emergency room physicians with a control group of family physicians in Riyadh referral hospitals.

The results of this study showed by using the PSQI ${ }^{35}$ that poor sleep quality was prevalent among emergency room physicians with a prevalence of $84 \%$ compared to $51 \%$ in family medicine physicians. Moreover, we found that falling asleep during daily activities is more prevalent among ER physicians with a prevalence of $41 \%$ compared to $14 \%$ reported in family medicine physicians. In addition, by using Becks Depression Inventory (BDI) ${ }^{37}$ it was found to be statically significant and indicating that $41 \%$ of emergency room physicians room physicians were depressed 
compared to $22 \%$ of family medicine physicians who were found to be depressed. Moreover, we found that poor sleep quality in emergency room physicians is strongly associated with depression.

A previous study conducted on male factory workers in Aseer, Saudi Arabia ${ }^{28}$ showed that poor sleep quality among shift workers was reported to be around $67.6 \%$ compared to only $20.3 \%$ in non-shift workers. Furthermore, another study was conducted on ER physicians in Pittsburgh ${ }^{38}$, reported that a percentage of almost $31 \%$ suffered from poor sleep quality. In comparison, the percentage of shift workers and ER physicians suffering from poor sleep quality are much less than what was reported in ER physicians in our recent study. Both studies focused on the effect of shift work on the sleep quality of the shift workers. It is possible that doctors in our study do more shifts than ER physicians in the American study.

\section{Limitations:-}

A limitation of this study was the relatively small sample size. However, the number of emergency room physicians in Riyadh is relatively small. Another limitations were that a higher proportion of the participants in this study were males.

\section{Conclusion:-}

Our study demonstrated that daytime sleepiness, poor sleep quality and depression are prevalent among emergency room physicians. Moreover, there was a strong correlation between poor sleep quality and depression. Efforts are needed to investigate the causes of these problems among emergency room physicians and to propose practical solutions.

\section{References:-}

1. Boivin DB, Boudreau, Impacts of Shift Work on Sleep And Circadian Rhythms. Pathol Biol (Paris), 2014 Oct; 62(5):292-301. dio: 10.1016/j.patbio2014.08.001

2. Gumenyuk V, Belcher R, Drake CL, Roth T, Differential Sleep, Sleepiness, And Neurophysiology In The Insomnia Phenotypes Of Shift Work Disorder. Sleep. 2015 Jan 1;38(1):119-26. doi: 10.5665/sleep.4336.

3. Lajoie P, Aronson KJ, Day A, Tranmer J, A Cross-Sectional Study Of Shift Work, Sleep Quality And Cardiometabolic Risk In Female Hospital Employees. BMJ Open. 2015 Mar 10;5(3):e007320. doi: 10.1136/bmjopen-2014-007327.

4. Ko SB, Night Shift Work, Sleep Quality, and Obesity. J Lifestyle Med, 2013 Sep;3(2)110-6. Epub 2013 Sep 30.

5. Palhares Ved C, Corrente JE, Masubara BB, Association Between Sleep Quality and Quality of Life in Nursing Professionals Working Rotating Shifts. Rev Saude Publica, 2014 Aug;48(4):594-601.

6. Harrington J M, Health Effects of Shift Work and Extended Hours of Work. Occup Environ Med 2001;58:6872 doi:10.1136/oem.58.1.68.

7. Jermendy G1, Nádas J, Hegyi I, Vasas I, Hidvégi T, Assessment of Cardiometabolic Risk Among Shifts Workers in Hungary. Health Qual Life Outcomes, 2012 Feb 1;10:18 doi: 10.1156/14777-7525-10-18.

8. Knutsson A, Hallquist J, Reuterwall C, Therorell T, Akerstedt T, Shiftwork and Myocardial Infarction: A CaseControl Study. Occup Environ Med, 1999 Jan;56(1):46-50.

9. Frost P, Kolstad HA, Bonde JP, Shift Work and The Risk of Ischemic Heart Disease - A Systemic Review of The Epidemiologic Evidence. Scand J Work Environ Health, 2009 May;35(3):163-79. Epub 2009 Apr 22.

10. Ellingsen T, Bender A, Gehani AA, Study of Shift Work and Risk of Cornonary Events. J R Soc Promot Health, 2007 Nov; 127(6):265-7.

11. Hermansson J, Gillander Gådin K, Karlsson B, Reuterwall C, Hallqvist J, Knutsson A, Case Fetality of Myocardial Infarction Among Shift Workers. Int Arch Occup Environ Health, 2015 Jul;88(5):599-605 doi:10.1007/s00420-014-z. Epub 2014 Sep 27.

12. Brown DL, Feskanich D, Sånchez BN, Rexrode KM, Schernhammer ES, Lisabeth LD, Rotataing Night Shift Work and The Risk of Ischemic Stroke. Am J Epidemiol, 2009 Jun 1;169(11):1370-7 doi:10.1093/aje/kwp056. Epub 2009 Apr 8.

13. Pan A, Schernhammer ES, Sun Q, Hu FB, Rotating Night Shift Work and Risk of Types 2 Diabetes; Two Prospective Cohort Studies on Women. PLoS Med, 2011 Dec;8(12):e1001141 doi:10.1371/journal.pmed.1001141. Epub 2011 Dec 6. 
14. Suwazono Y, Sakata K, Okubo Y, Harada H, Oishi M, Kobayashi E, Uetani M, Kido T, Nogawa K, Long-Term Longtidinal Study On The Relationship Between Alternating Shift Work And The Onset Of Diabetes Mellitus In Male Japanese Workers. J Occup Environ Med, 2006 May;48(5):455-61.

15. Morikawa Y, Nakagawa H, Miura K, Soyama Y, Ishizaki M, Kido T, Naruse Y, Suwazono Y, Nogawa K, Shift Work and The Risk of Diabetes Mellitus Among Japanese Male Factory Workers. Scand J Work Environ Health, 2005 Jun;31(3):179-83.

16. Guo Y, Liu Y, Huang X, Rong Y, He M, Wang Y, Yuan J, Wu T, Chen W, The Effects of Shift Work on Sleeping Quality, Hypertension and Diabetes in Retired Workers. PLoS One, 2013 Aug 16;8(8):e71107 doi:10.1371/journal.pone.0071107 eCollection 2013.

17. Kroenke CH, Spiegelman D, Manson J, Schernhammer ES, Colditz GA, Kawachi I, Work Characteristics and Incidence of Type 2 Diabetes in Women. Am J Epidemiol, 2007 Jan 15;165(2):175-83. Epub 2006 Oct 27.

18. Young J, Waclawski E, Young JA, Spencer J, Control of Type 1 Diabetes Mellitus and Shift Work. Occup Med (Lond), 2013 Jan;63(1):70-2 doi:10.1093/occmed/kqs176. Epub 2012 Sep 30.

19. Ellingsen T, Bener A, Gehani AA, Study of Shift Work and Risk of Coronary Events. J R Soc Promot Health, 2007 Nov;127(6):265-7.

20. Schernhammer ES, Laden F, Speizer FE, Willett WC, Hunter DJ, Kawachi I, Colditz GA, Rotating night shifts and risk of breast cancer in women participating in the nurses' health study. J Natl Cancer Inst. 2001 Oct 17;93(20):1563-8.

21. Lajoie P, Aronson KJ, Day A, Tranmer J, A cross-sectional study of shift work, sleep quality and cardiometabolic risk in female hospital employees. BMJ Open. 2015 Mar 10;5(3):e007327. doi: 10.1136/bmjopen-2014-007327.

22. Guo Y, Rong Y, Huang X, Lai H, Luo X, Zhang Z, Liu Y, He M, Wu T, Chen W,Shift work and the relationship with metabolic syndrome in Chinese aged workers. PLoS One. 2015 Mar 11;10(3):e0120632. doi:10.1371/journal.pone.0120632. eCollection 2015.

23. Machi MS, Staum M, Callaway CW, Moore C, Jeong K, Suyama J, Patterson PD, Hostler D, The relationship between shift work, sleep, and cognition in career emergency physicians. Acad Emerg Med. 2012 Jan;19(1):8591. doi: 10.1111/j.1553-2712.2011.01254.x. Epub 2012 Jan 5.

24. Jermendy G, Nádas J, Hegyi I, Vasas I, Hidvégi T, Assessment of cardiometabolic risk among shift workers in Hungary. Health Qual Life Outcomes. 2012; 10: 18. doi: 10.1186/1477-7525-10-18.

25. Itani O, Kaneita Y, Murata A, Yokoyama E, Ohida T. Association of onset of obesity with sleep duration and shift work among Japanese adults. Sleep Med. 2011 Apr;12(4):341-5. doi: 10.1016/j.sleep.2010.09.007. Epub 2011 Mar 5.

26. Ko SB,Night Shift Work, Sleep Quality, and Obesity. J Lifestyle Med. 2013 Sep; 3(2): 110-116.

27. Palhares Vde C, Corrente JE, Matsubara BB, Association between sleep quality and quality of life in nursing professionals working rotating shifts. Rev Saude Publica. 2014 Aug; 48(4): 594-601. doi: 10.1590/S00348910.2014048004939.

28. AlMetrek M, Effect of Shift-Work on Sleeping Quality of Male Factory Workers in Saudi Arabia. Natl J Physiol Pharm Pharmacol. 2014; 4(1): 61-68. doi: 10.5455/njppp.2014.4.100820131.

29. Jafari Roodbandi A, Choobineh A, Daneshvar S, Relationship between Circadian Rhythm Amplitude and Stability with Sleep Quality and Sleepiness among Shift Nurses and Health Care Workers. Int J Occup Saf Ergon. 2015;21(3):312-7. doi: 10.1080/10803548.2015.1081770.

30. Uehli K, Miedinger D, Bingisser R, Dürr S, Holsboer-Trachsler E, Maier S, Mehta AJ, Müller R, Schindler C, Zogg S, Künzli N, Leuppi JD,Sleep quality and the risk of work injury: a Swiss case-control study. J Sleep Res. 2014 Oct;23(5):545-53. doi: 10.1111/jsr.12146. Epub 2014 Jun 2.

31. Vallières A, Azaiez A, Moreau V, LeBlanc M, Morin CM, Insomnia in shift work. Sleep Medicine, Volume 15, Issue 12, December 2014, Pages 1440-1448. doi:10.1016/j.sleep.2014.06.021.

32. Christian Veauthier, Gunnar Gaede, Helena Radbruch, Klaus-Dieter Wernecke, and Friedemann Paul. Poor Sleep in Multiple Sclerosis Correlates with Beck Depression Inventory Values, but Not with Polysomnographic Data. 2016 Jan 18. Doi: 10.1155/2016/8378423

33. Raniti MB, Allen NB, Schwartz O, Waloszek JM, Byrne ML, Woods MJ, Bei B, Nicholas CL, Trinder J. Sleep Duration and Sleep Quality: Associations with Depressive Symptoms Across Adolescence. Behav Sleep Med, 2016 Jan 8:1-18

34. Wells RD, Day RC, Carney RM, Freedland KE, Duntley SP. Depression predicts Slelf-reported Sleep Quality in Patients With Obstuructive Sleep Apnea. Psychosom Med. 2004 Sep-oct;66(5):692-7 
35. Buysse DJ, Reynolds CF 3rd, Monk TH, Berman SR, Kupfer DJ, The Pittsburgh Sleep Quality Index: a new instrument for psychiatric practice and research. Psychiatry Res. 1989 May;28(2):193-213.

36. Johns MW , A new method for measuring daytime sleepiness: the Epworth sleepiness scale. Sleep. 1991 Dec;14(6):540-5.

37. Beck AT, Ward CH, Mendelson M, Mock J, Erbaugh J, An Inventory for Measuring Depression. Arch Gen Psychiatry. 1961 Jun;4:561-71.

38. Machi MS, Staum M, Callaway CW, Moore C, Jeong K, Suyama J, Patterson D, Hostler D.The Relationship Between Shift Work, Sleep, and Cognition in Career Emergency Physicians. Academic Emergency Medicine, Volume 19, Issue 1, pages 85-91, January 2012. DOI: 10.1111/j.1553-2712.2011.01254.x 